\title{
Ciibsaa: Maccaa Oromo Indigenous Soil Fertilizing Mechanism in East Wallagga Zone, Ethiopia
}

\author{
Kamil Mohammed; Megersa Regassa; Waktole Hailu \\ Department of Oromo Folklore and Literature, Jimma University College of Social Sciences and Humanities, Ethiopia
}

http://dx.doi.org/10.18415/ijmmu.v5i6.696

\begin{abstract}
This research was conducted in three districts from East Wallaggaa Zone of Ethiopia. The purpose of the study was to explore ciibsaa Indigenous soil fertilizing mechanisms practices for fertilizing farmland and garden. The objective of this research was to explore the contributions of Oromo indigenous knowledge in soil fertility management. To achieve this goal, we employed different data collection methods. In primary data collection, both individual and group interviews were meticulously used. Key informants were selected purposively and the selected people were extensively interviewed. We made indepth interviews with elders, farmers, community leaders and knowledgeable persons. Focus group discussions were held, observations were made and informal discussions were employed to get relevant data on this topic. The findings revealed that the Oromo people has indigenous knowledge of soil fertilizing mechanism and the ways they used to classify soil and how the land becomes fertile after ciibsaa indigenous treatment. Nowadays, this indigenous soil fertility management is declining because of various factors. Those factors are population growth, decreasing number of livestock and adaptation of chemical fertilizer.
\end{abstract}

Keywords: Ciibsaa; Soil Fertilizing Mechanism; Maccaa; Oromo; Ethiopia

\section{Introduction}

Soil fertility is declining in many parts of sub-Saharan Africa (SSA) (Stoorvogel et al., 1993). One of the major constraints to crop production faced by smallholder subsistence farmers is the inadequate supply of nutrients (Quinones et al., 1998; Shapiro and Sanders, 1998). Farmers are either entirely abandoning the traditional practice of using natural fallow to restore soil fertility, or are unable to leave land fallow for long enough for it to be effective. The use of mineral fertilizers is declining as they are increasingly beyond the means of most small-scale farmers (Larson and Frisvold, 1996).

The working definitions (Ellen \& Harris 2002:2-6) indigenous knowledge in development context may relate to any knowledge held more or less collectively by a population, informing understanding of the world. It may pertain to any domain, particularly natural resource management in development currently. It is community based, embedded in and conditioned by local tradition. 
It is culturally informed understanding inculcated into individuals from birth onwards, structuring how they interface with their environments. It is also informed continually by outside intelligence. This shown by the range of alternative terms used for indigenous knowledge by different writers vying for prominence and claiming to more representative as they argue over the content of and approaches to this field. They include local knowledge, rural people's knowledge, insider knowledge, indigenous technical knowledge, traditional environmental knowledge. It also includes People, science and folk knowledge. Macchi (2008) explains about indigenous knowledge of the people, "traditional societies in many cases have built up knowledge over long periods about changes in the environment and have developed elaborated strategies to cope with these changes". However, traditional knowledge systems in moderation and adaptation have for a long time been neglected in climate change policy formulation and implementation and have only recently been taken up into the climate change discourse.

Mamo (2006) portrays the relationships between land and lineage, focusing on historical, economic and ritualistic or religion relationships. Among Arsi Oromo possessing and transmitting land is not only the matter of providing, but also it is a moral and social responsibility. In whatever case, a man who lost his land, he considered as he 'ate' his father 'ear'. This is means insulting as dishonor and spoils his father's name. Land was thought as an archive of a qomo (clan or lineage) history in the sense that a group of agnatic ally related men who would also pass it on to their heirs used a given territory of land. Moreover, this was a great inducement for proper management of land and its resources to symbolize and reflect the strength and social prestige of the lineage. Equally important was that land was controlled communally by qomo (kinship) with emphasis on equality and there was no taxation (Asmarom, 1973). The farmers' preference for level land might be explained by the higher nutrient leaching on low wet plots (Brouwer and Powell 1998). In all households, waste and animal droppings were swept daily on a heap located at a protected area inside or outside the compound. This research tried to study how the Oromo indigenous knowledge applied in increasing soil fertility by using Ciibsaa. Different scholars in the world have considered the link between indigenous values and environment. Oromo indigenous knowledge is based on inherited experience gained over many generations and is passed on verbally from generation to generation and by observing the actual techniques of enriching soil fertility.

According to Pound and Ejigu (2005) the farmer soil classification is strongly based on the requirements for most favorable crop production as a function of the climatic conditions of the area, and its application is oriented towards a traditional and sustainable form of agriculture. Yet, Oromo indigenous way of fertilizing soil had contributed for the sustainable environment and crop production since time immemorial. The Oromo used indigenous knowledge they inherit from their ancestors to keep their farmland fertile. The central points on which this study focuses is Ciibsaa, which are indigenous mechanisms of fertilizing soil among Maccaa Oromo in East Wallaga. Scholars did not give attention to this indigenous skills and knowledge of soil fertility as such from cultural point of view.

\section{Methodology}

The source of data for this study is both primary (oral sources, archival materials etc.) and secondary sources was used. The primary data were depending on a systematic collection of oral information from both individual and group interviews were meticulously gathered. Fifteen Key informants selected purposively and the selected people interviewed extensively. We made in-depth interviews with elders, farmers, community leaders and knowledgeable persons. To give the opportunity to raise further information and to understand the ways in which indigenous customs transmitted, the researchers used open-ended questions.

In-depth interview sessions made to obtain information on the status of indigenous knowledge in keeping soil fertility. Researchers were interviewed 15( fifteen) proper individuals including the farmers, 
community leaders, natural resource experts, elders both female and male, the districts Cultural and Tourism, Agriculture and Rural development. Throughout the study, the informants were asked to illustrate the indigenous knowledge of Ciibsaa in fertilizing soil and its role in increasing crop productivity /or any other components related to the practice. We captured photographs and samples of the Ciibsaa in the study area.

Through informal interviews, different informants from different categories of the society who are knowledgeable about the culture of the study community were interviewed in different places like on coffee ceremony and on farming place. This instrument were helpful for us to get information about people's attitudes towards indigenous way of keeping soil fertility and its significance in relation with current governmental approach to issues like tracing development in scientific ways. Six focus group discussions which will include eight participants in each were carried out. The participants of the focus group discussion were purposely selected from farmers known by their knowledge, past experience, degree of participation in the study under discussion and position of the culture in the area were incorporated in their category with women and experts from culture and tourism and from natural resource expert and Development Agents.

Observation is one of research methods used in cultural studies. In this research observation were used to collect data related to Ciibsaa in farmers farming land. The researchers observed women cultivating crops by Ciibsaa. During the fieldwork, we gathered information according to research ethics. We took agreement from research review board of Jimma University (our college). The informants consent was verbal consent because it is difficult to use written consent since majority of the population have no reading skill and they did not want to sign. During the observations, interview and group discussion, we informed all informants about purpose, methods and importance of the research and participation they entail. In the data collection procedure, we avoided violation of the promise of privacy. We gave all informants the right to withdraw from the study.

\section{Review of Related Literature}

\section{Farmer's knowledge on soil fertility}

The farmer soil classification strongly based on the requirements for most favorable crop production as a function of the climatic conditions of the area, and its application is oriented towards a traditional and sustainable form of agriculture. As a result of population growth, the current sustainable land-use practices in coffee producing area is coming under pressure and will inevitable have to adapt to changes in the physical and political environment. This process may ultimately lead to a more intensive land-use based on mechanization, chemical fertilizer application and new crop types. Such rapid changes represent a risk of the farmers losing their traditional knowledge about the local soils, traditional management procedures, including crop types, their rotation, and length of the fallow period and fertilizer applications.

The farmers' soil classification system was based on the texture and color of the soil, and on the topography. The yield potential of the land was assessed using indicators such as dark soil color, texture, and a high vegetation density on a flat surface. Sloping lands, especially those directed to the east, or light colored soils with a high density of grasses were considered as poor farmland. The farmers" preference for level land might be explained by the higher nutrient leaching on low wet plots (Brouwer and Powell 1998).

In all households, waste and animal droppings were swept daily on a heap located at a protected area inside or outside the compound. The farmers ranked the importance of the ingredients of this farmyard manure in the following order: animal feces feed leftover are litter, grass kitchen residues ash. 
They had a clear concept of the quality of the muck of the different animal species. Cattle dung was the most preferred manure, followed by small ruminant droppings. Donkey droppings ranked last in all cases, because it was believed to cause fungus diseases in millet at the seedling (Irene Hoffmann 2002).

This research were also tried to determine whether this applies to Oromo or not and whether or not Oromo indigenous knowledge was also revive and contribute for environmental protection. Almost all of the accounts have nothing more than sideline references to the topic. A number of popular and professional scholars have used the relation of Oromo indigenous beliefs and environment as points of references while studying other themes. This study were tried to discover how far the Oromo indigenous knowledge applied in increasing soil fertility by using Ciibsaa. We studied these practice to come up with concrete evidence and exhaustive information on the related issues in the study area.

\section{Result and Discussion}

\section{Concepts of ciibsaa}

The word ciibsaa is derived from the Oromo term ciibsuu which literally means 'making lay down'. In this case, ciibsaa is the land that covered by manure or dung of cattle, donkey, and mule. The process of covering the land with the dung of these livestock is ciibsaa ciibsuu. Depending on the season in which it practiced, there are two types of ciibsaa ciibsuu; one is dhoqqeessuu and the other is dikeessuu. Dhoqqeessuu is the ciibsaa that covered on the farmland during the summer season; it is rainy time so that the dung is wet. Dikee (dikeessuu) is that of the winter season; it dry season so that the dung is dry. Ciibsaa is one of indigenous soil fertilizing mechanisms among Maccaa Oromo of East wallaggaa. It is a mechanism used to make the farmland fertile by using cattle dung. Practicing cibsaa in the absence cattle was unthinkable so that here below we had a tried to discuss the about cattle Oromo relationship.

The Oromo has a variety of management techniques practiced by farmers in the study areas. Some of these include ciibsaa, kosii, crop rotation, manuring, mixed cropping, fallowing, and planting legumes. Farmers in most cases tried to perform problem solving and adaptation experiments.

\section{Ciibsaa preparation}

The farmers construct ciibsaa on their farmland which is used as a temporary fences or kraals. The kraals for ciibsaa are different from others by their ways of practicing. The explained. The literatures seem to be uneven in both quantity and quality.

Equipment needed for constructing ciibsaa was tree of different size with two arm, ropes from tree or natural ropes. The fence starts with standing pall in rectangular form in to four feet distance. The kraal was filled by trees from the pole stands in rectangle to caver it. If once the kraal was constructed there was a techniques of effective used of tree needed for ciibsaa construction. Ciibsaa kraal is very important to simplify the labor force used in cutting and porting to the farmland where the ciibsaa were constructed because they use tree once constructed for several time by change over the farmland in the study areas. The responsible body to construct the kraal was men or youngsters but in the absence of husband, the women can construct the kraal for the cattle as well change ciibsaa over her homestead or farm yard process or construction activities. According to our informants, there are beliefs in Oromo culture in relation to ciibsaa. For instance using cibsaa tree or tree from ciibsaa kraal cannot be used for firewood, if any one reach a people or person a while constructing ciibsaa he she cannot pass over without helping. 
Of all the local materials involved in soil fertility management, manure is the most highly valued by farmers. They realize that it is the most important factor in ensuring consistent yields as it brings nitrogen, organic matter and microbial life to the soil. Farmers use crop residues rationally, after weighing up the competing uses of these materials for fuel, fodder and soil improvement. Extension staff tends to ignore the fuel and fodder functions of crop residues. More would be gained by identifying and supporting substitute fuel and fodder sources (such as trees to be planted on farm margins) so that a greater proportion of crop residues could be returned to the soil.

Practice of ciibsaa help the farmer to fertile their soil with very low cost and natural way the cattle waste out their waste product which has nutrient used for soil fertility. The land become fertile through this mechanism is long last with its fertility and gives high product. In addition the land fertile through ciibsaa can grow any kind of crop without those which grow on none fertile land like nuugii (guzotia abyssinica), talba (litreed) etc.

\section{Dallaa ijaaruu /kraal preparation}

Dallaa is the cattle fence or house made from different trees in the farmer's compound for the sake of various needs. The primary goal of making kraal for cattle's is to control their cattle in one place because the Oromo have many cows so it is difficult to construct house.

Dallaa is the kraal of the cattle that built in rectangular form and continuously rebuilt within not more than a week. By this process, it covers large area of farmland by the ciibsaa. The gate from which the cattle enter to the kraal is karra (entrance). There are different cultural beliefs in relation to dallaa (kraal of cattle). First, in building or changing the kraal from enriched with dug or fertilized land to the unfertilized land, after finishing building of the kraal, the person or persons built the kraal sits his/their heel and prays to the Waaqaa (God). The thanks giving prayer to Waaqaa for his charity on their cattle, made him/them to be able to build a kraal, and having ciibsaa to grow up the crops by fertilizing the land. The person sits on his heel at the center of the rebuilt kraal and says:

Yaa Waaq galata kee
Oh Waaqa thanks
Dallaa kana situu naa kenne
Rimaa haphee naa gidhi
Waatii haadha jala naa bulchi
Korma naa goobsi
Make the bull fat

For instance, the person who does not have cattle (iyyeessaa) takes cattle from the rich man (sooressa) and use the ciibsaa for himself. This done by the agreement with the sooressaa and the iyyeessaa. The soressaa give the cattle when he/she become unable to keep his/her cattle because of large cattle population, lack of land, lack of grass, lack of cattle keeper or human power and lack of water. The iyyeessaa take or keeps the cattle to use the ciibsaa and grow up crops by using manure of the cattle as the fertilizer. The iyyeessa have no any property right over the cattle except using the manure as fertilizer. The person who received the cattle is responsible for keeping cattle in safe and building kraal. Sometimes the cattle owner can give one or two cow for the iyyeessaa to use its milk and milk products (cheese and butter); however, the cow and the calf belongs to the cattle owner. This is to initiate that person to keep cattle safely. This way of agreement and cooperation is kaayaa. The primary aim of kaayaa agreement is ciibsaa. The cattle owner has no any right over using ciibsaa of the cattle. It belongs to the person who received the cattle to use the ciibsaa. Therefore, by this kaayaa agreement the poor fertilizes his/her land by ciibsaa traditional soil fertilizing mechanism.
This kraal is your gift

Make the bull productive

Qotiyyoo qambarriirra naa bulchi

Horaa! Kuma horaa!

Make the bull fat
Korma cirrii naa godhi 
The other taboo or restriction in relation to cattle is when anybody meets the person/s building the kraal, he has to help him/them. It is taboo to pass over without helping that person. This is because, it considered that the cattle is not only property of the owner, rather it belongs to whole people. Therefore, everyone should work for the safe of cattle regardless of the ownership. Regarding this, Oromo proverb says "Horiin abbaa hin beeku" which means, "cattle do not know its owner". That means, the cattle could not refuse to be used by other person. They are obeyed to serve everybody regardless of the ownership. Therefore, everybody is responsible for their protection, including building their kraal.

The other traditional restriction concerning the kraal is that it does not built on the day of caginoo. For the Oromo caginoo days are Monday, Wednesday, and Friday. On these days, one cannot build dallaa for ciibsaa purpose. If the dallaa built on these days, it traditionally believed that it is bad luck for cattle. The cattle could die by disease, lightening, and other fatalities. Additionally, it is traditionally believed that the ciibsaa itself would be useless; it would not grow the crop.

It is against safuu to use kraal as firewood. It is against safuu to burn any piece of kraal. If someone use kraal as firewood, it is believed that the Waaqaa could punish him and he will not get cattle and then kraal afterwards. If cattle vanished or every cattle died from someone, he/she could not destroy the kraal. Instead, he/she safely preserve the kraal. It is because, even if the cattle vanished, they respect and safely preserve the kraal.

At the morning, when someone takes the cattle from the kraal, he/she should wait the cattle until they put the dung in the kraal. This is done because, when the cattle go out of the kraal, it could put it in the field anywhere out of the kraal. Therefore, the dung cannot be used as ciibsaa and it could not fertilize the farmland. Therefore, after awaking the cattle, one should wait few minutes until they drop their dung in the kraal.

The kraal should be built broadly. Its width should be more than enough to hold the cattle live in it. This shows two things; it help the cattle to live in it freely; the other is it shows the ambition of the owner to have more cattle and have wider kraal. It is laborious for one person to build the kraal alone. There is a personification in relation to the workload in building the kraal alone. The kraal said this: "tokkoon nan haasa'a, lama na ijaara, sadii naan haasa'a" which means, "I win one person, two people build me, three people win me". This means, it is difficult for one person to build a kraal alone. For two people it is somewhat easy. However, for three people, it is very easy work. They can finish it without fatigue. This activity keeps the relationship between the neighbors to work together.

\section{Land use in Maccaa Oromo}

Land is a symbol of status, and people are apt to value the quantity of it for its own sake. In former times, nobody was allowed to pass it on to another clan without the consent of his fellowclansmen. Nowadays, this norm has lost much of its force. For a land-use system to be sustainable requires conservation not only of soil but of the whole range of resources on which production depends on the land. They employ different indicators of knowing whether the soil is fertile or not. The major indicator mentioned by farmers is amount of crop yield. Farmers use both indigenous and modern methods of maintaining soil fertility. While they use their land by dividing according to their significances. The societies named their land based on different criteria are their significance and distance from the home. Lafa qe'ee (homestead), Lafa Qonnaa (farmland), lafa dheedichaa (communal grazing land).

The Oromo farmers classified soils based on what they saw and felt about that particular soil. There were certain inherent factors that farmers used to classify and characterize soil types. The most important ones were color, fertility, land type and depth of the soil. Farmers are easily able to differentiate 
between soil types in the area, and have local names for different soil types. Farmers consider soil as a living entity that grows, matures, becomes old and even dies so that even grass cannot grow lafti akkuma namaa dhukkubsata 'sick soil' can be cured with the right inputs and a tired soil can be revitalized. For this kind of land the society said 'lafti kun borqoofte' or 'lafa borqii'. Farmers are aware where each soil type exists, and know the crop type grow on each soil type within their own land. Farmers are also able to identify variability between soils at their field.

\section{Conclusion}

The land that covered by manure or dung of cattle, donkey, and mule. The process of covering the land with the dung of these livestock is ciibsaa ciibsuu. Farmers in most cases tried to perform problem solving and adaptation experiments. The application of soil fertilizing techniques, increasing the land fertility by the use of indigenous knowledge. The application of their agricultural knowledge and practices, the Maccaa Oromo have been able to obtain surplus harvests and maintain harmonious and balanced relationships between crop cultivation, livestock raising, plant life, and the environment. However, the most direct and primary requirement for sustainability is to maintain soil fertility. Farmers perceive soil fertility in terms of the capacity of soils for long-term productivity, their previous crop cultivated, manure requirement, and cultivability.

Farmers classified soils based on what they saw and felt about that particular soil. There were certain inherent factors, which farmers used to classify and characterize soil types. The most important ones were color, fertility, land type and depth of the soil. Farmers are easily able to differentiate between soil types in the area, and have local names for different soil types. In study areas people classified the soil into biyyee diimaa (red soil), biyyee Kootichaa, biyyee suppee, biyyee gurraacha (black soil) and biyyee cirrachaa(sandy soil).

\section{Acknowledgment}

We would like to thanks Jimma University for the sponsorship of this project. This research would have not been successful without the cooperation of informants, who provided us all the information we sought and we truly grateful for that. Our special thanks also go to all key informants.

\section{References}

Asmarom Leggesse.(1973). Gadaa: Three Approaches to Study of African Society. New York: Free Press.

Bitwy Warszawskiej. (2005). Forestry and our cultural heritage. Ministerial Conference on the Protection of Forests in Europe Liaison Unit Warsaw Sunne, Sweden.

Lambert Bartels. (1983). Oromo religion: myths and rites of the western Oromo of Ethiopia an attempt to understand. Berlin: Dietrich Reimer Verlag.

Larson, B.A., Frisvold, G.B., (1996). Fertilizers to support agricultural development in subSaharan Africa. What is needed and why? Food Policy.

Mamo Hebo. (2006). Land, Local Custom, and State Policies: Land Tenure, Land Disputes and Disputes Settlement among the Arsii Oromo of Southern Ethiopia: Kyoto. 
Mirjam macchi. (2008). Indigenous and traditional peoples and climate change. Cambridge university press, Cambridge.

Okupau. (1978). West African religion. FEP International Private Limited.

Piter Mwaura.(2008). Indigenous in disaster management in Africa. Courtesy of drought Monitoring center, Nairobi, Kenya.

Posey, Darrell and Graham Dutfield .(1996). Beyond Intellectual property towards traditional resource rights for indigenous peoples and local communities. International Development research center. Ottawa, Canada.

Roy Ellen, Peter Parkes, Alan Bicker(ed). (2000). Indigenous Environmental Knowledge and its Transformations Critical Anthropological Perspectives: Harwood academic publishers. University of Kent at Canterbury UK.

Stevenson, M.G. (1998). Traditional knowledge and environmental management: from commodity to process. Paper for NAFA conference, Celebrating Partnerships. September 1418. Prince Albert, SK.

W. Bruce Campbell and Silvia López Ortiz. (2011). Integrating Agriculture, Conservation and Ecotourism: Examples from the Field: Springer Dordrecht Heidelberg London New York.

\section{Copyrights}

Copyright for this article is retained by the author(s), with first publication rights granted to the journal.

This is an open-access article distributed under the terms and conditions of the Creative Commons Attribution license (http://creativecommons.org/licenses/by/4.0/). 